\title{
High frequency rotational ablation: an alternative in treating coronary artery stenoses and occlusions
}

\author{
Ulrich Dietz, Raimund Erbel, Hans-Jürgen Rupprecht, Stephan Weidmann, Jürgen Meyer
}

Abstract

Objective-To prove the safety and effectiveness of high frequency rotational ablation of coronary artery stenoses and occlusion in humans.

Subjects-106 patients with symptoms (91 men, 15 women) who had 67 significant stenoses, mainly types $B$ and $C$, and 46-chronic occlusions.

Main outcome measures-Mean change in diameter stenosis after rotational angioplasty alone and in combination with percutaneous transluminal coronary angioplasty immediately after treatment and 24 hours and six months later; restenosis rates at six months; complications of treatment.

Results-Rotational ablation could not be used in five stenoses and 16 chronic occlusions because of inability to reach or cross the lesion with the Rotablator guide wire. In four cases rotational ablation failed. Initial angiographic and clinical success by rotational ablation was achieved in 40 of the 67 stenoses $(60 \%)$ and in 18 of the 46 chronic occlusions (39\%). Additional balloon angioplasty was performed in 45 patients, increasing the success rates to $79 \%$ and $54 \%$, respectively. In the 62 stenoses treated by rotational ablation the angiographic diameter stenoses were reduced from $76 \%$ (SD $14 \%$ ) to $32 \%$ (14\%) after Rotablator treatment alone and from $75 \%(11 \%)$ to $33 \%(17 \%)$ with additional balloon angioplasty. In the 30 chronic occlusions treated by rotational ablation the angiographic diameter stenoses were reduced to $38 \%(18 \%)$. At six months angiographic restenosis was evident in nine of the $25(36 \%)$ stenoses treated with rotational ablation alone, in seven of the $22(32 \%)$ stenoses treated with rotational and balloon angioplasty, and in 14 of the $24(58 \%)$ chronic occlusions. There were no procedural deaths and two patients (2\%) underwent emergency coronary artery bypass grafting. Although no transmural infarction occurred, there were five (6\%) non- $Q$ wave infarctions (two embolic side branch occlusions, two subacute occlusions, and one acute occlusion). Clinically insignificant slight increases in creatine kinase activity were seen in five patients (6\%). Severe coronary artery spasm unresponsive to medical treatment was provoked in seven cases $(8 \%)$.
Conclusions-High frequency rotational ablation is a safe and effective method for treating type $B$ and $C$ coronary artery lesions with results comparable to percutaneous transluminal coronary balloon angioplasty. The combined use of rotational ablation and balloon angioplasty is feasible and is necessary in about half of all procedures, in most cases because the lumen created by the biggest burr is too small.

\section{(Br Heart f 1993;70:327-336)}

Balloon angioplasty of coronary artery lesions with certain morphological characteristics is associated with a lower success rate and an increased complication rate. ${ }^{1-4}$ To improve the results in complicated lesions alternative interventional procedures have been developed based on ablation of atherosclerotic plaque. ${ }^{5-7}$ One of these methods is high frequency rotational ablation, ${ }^{8-11}$ which by its mechanism of action-that is, fracturing and pulverising hard and calcified materialpredominantly ablates the atherosclerotic plaque, causing minimal damage to the undiseased vessel wall. ${ }^{12}$ Although Dotter effects have been shown, their frequency and extent are low, especially when the burr is advanced slowly and the plaque is reduced in steps with different burr sizes. ${ }^{13}$ Preliminary reports have documented the feasibility and effectiveness of high frequency rotational ablation in human coronary artery lesions. ${ }^{14-16}$ We investigated its effectiveness and safety in a larger group of human coronary artery lesions, particularly of the B and C types.

\section{Patients and methods}

From March 1988 to December 1991 rotational ablation was attempted in 106 patients (91 men and 15 women, mean age 59 (SD nine years). Forty of them had had a myocardial infarction in the area of the diseased vessel. All patients had either episodes of angina or positive results on stress testing. Single vessel coronary artery disease was present in 67 patients, double vessel disease in 27 , and triple vessel disease in 12; five patients had undergone coronary artery bypass grafting.

Sixty seven stenoses and 46 chronic occlusions (mean duration of occlusion four (2) months) were selected for rotational ablation. Thirty four stenoses and 28 occlusions were 
located in the left anterior descending artery, 15 stenoses and 10 occlusions in the left circumflex artery, 16 stenoses and eight occlusions in the right coronary artery, and two stenoses in the diagonal branches. The stenotic lesions were classified according to the American Heart Association guidelines ${ }^{3}$ as type $A$ in five cases, as type $B$ in 37 , and as type $C$ in 25 . A fresh lesion was treated 102 times and restenosis 11 times.

\section{PROTOCOL}

Inclusion and exclusion criteria were those currently used for balloon angioplasty. Patients with a type B or C coronary artery lesion were selected preferentially. All patients gave written informed consent. The investigation was performed according to the declarations of Helsinki, Tokyo, and Venice.

DRUGS

All patients received $20 \mathrm{mg}$ nifedipine two times a day, and an initial group of patients received a daily dose of $500 \mathrm{mg}$ aspirin (which was later reduced to $100 \mathrm{mg}$ a day), starting one day before the procedure and continuing for six months. An intravenous infusion of dextran $40(100 \mathrm{ml} / \mathrm{h})$, nifedipine $(0.5 \mathrm{mg} / \mathrm{h})$, and glyceryl trinitrate $(3 \mathrm{mg} / \mathrm{h})$ was given one hour before the procedure. At the beginning of catheterisation an intravenous bolus of $10000 \mathrm{U}$ heparin was administered followed by an infusion at 2000 $\mathrm{U} / \mathrm{h}$. The infusions were continued for 48 hours. After each series of rotational ablation glyceryl trinitrate and heparin were administered between meals when appropriate. Before treatment of the right coronary artery $1.0 \mathrm{mg}$ atropine was administered as an intravenous bolus.

\section{ROTATIONAL ABLATION DEVICE}

The Rotablator system (Heart Technology Bellevue, Washington) includes a catheter unit for one time use and a control panel. The catheter consists of a spiral drive well, which is coated by a 3 French Teflon sheath. At the distal end there is a bean shaped metal tip of various sizes $(1 \cdot 25,1 \cdot 5,1 \cdot 75$, and $2 \cdot 0$ $\mathrm{mm})$. Diamond chips of $30 \mu \mathrm{m}$ are embedded in the distal portion of the burr. The proximal end of the catheter is connected to an air driven turbine. At an air pressure of 4-5 atmospheres the turbine rotates the drive well up to $190000 \mathrm{rpm}$. For lubrication and convection of heat a saline infusion perfuses the catheter at a basal perfusion rate of 3 $\mathrm{ml} / \mathrm{min}$ and during rotation at $12 \mathrm{ml} / \mathrm{min}$. The catheter has a central coaxial lumen that allows tracking of the catheter via a 0.009 inch steel guide wire, which has a flexible distal end 0.014 inch wide. When the guide wire is in position the burr is advanced and can be tracked back and forth by pushing the advancer knob without moving the guide wire, which is fixed by a brake.

\section{PROCEDURE}

For the treatment a 9 French introducing sheath and a 9 French guiding catheter were used. As the Rotablator guide wire is difficult to guide in the coronary artery system, a 3 French recanalisation catheter (Schneider) was placed across or in front of the lesion when a 0.014 inch guide wire (Advanced Cardiovascular Systems) could not be passed. It was then replaced by the Rotablator guide wire, which was positioned across the coronary artery lesion to the distal side. During positioning of the guide wire all force was avoided. The recanalisation catheter was then removed, and the burr was advanced in front of the lesion with slow or no rotation ( $<50000 \mathrm{rpm}$ at 1-2 atmospheres). The burr was slowly $(1 \mathrm{~mm} / \mathrm{s})$ tracked back and forth at 160000 to $180000 \mathrm{rpm}$ by pushing the advancer knob for up to $10 \mathrm{~s}$. This procedure was repeated up to three times for each burr size so long as there was a noticeable decrease in rotational frequency while the burr was passing through the lesion. To avoid additional longitudinal shear stress to the vessel wall the burr was always rotating when passing through the lesion. Between each rotational series we waited for at least 30 seconds or until electrocardiographic abnormalities disappeared. We began with a small burr in high grade lesions and occlusions and continued with a larger burr unless the result was satisfactory. When the outcome after the use of at least two burrs was still not successful (see below), the intervention was followed by balloon angioplasty. A balloon catheter guided by a wire was used which could be exchanged over the Rotablator guide wire. Balloon size was chosen to avoid any overdilatation of the vessel. Inflation pressures were 4 to 6 atmospheres and the inflation duration 30 to 60 seconds. Follow up angiography was performed 10 to 24 hours after the intervention using the same projections and drug treatment as before. We tried to obtain another angiogram six months later with identical projections. Patients were pretreated with sublingual glyceryl trinitrate $(0.8 \mathrm{mg})$ (Pohl-Boskamp).

\section{ANGIOGRAPHIC MEASUREMENT}

The best projection for quantitative analysis of the stenosis was determined at the beginning of the intervention. All measurements were taken in this projection only, which was also used in all follow up angiograms. We calculated the absolute and relative minimal stenosis diameters according to the assumptions given by Brown et al. ${ }^{17}$ Callipers were calibrated against the outer diameter of the guiding catheter seen in the same view. To facilitate accurate calibration the guiding catheter tip was filmed without containing contrast media.

Initial angiographic success by rotational ablation was defined as a reduction of $\geqslant 20 \%$ in diameter stenosis or to $\leqslant 50 \%$ of luminal diameter achieved by rotational ablation and the absence of severe cardiac events (myocardial infarction, coronary artery bypass grafting, or death). Overall success was defined as meeting the above mentioned criteria for angiographic success and the absence of 


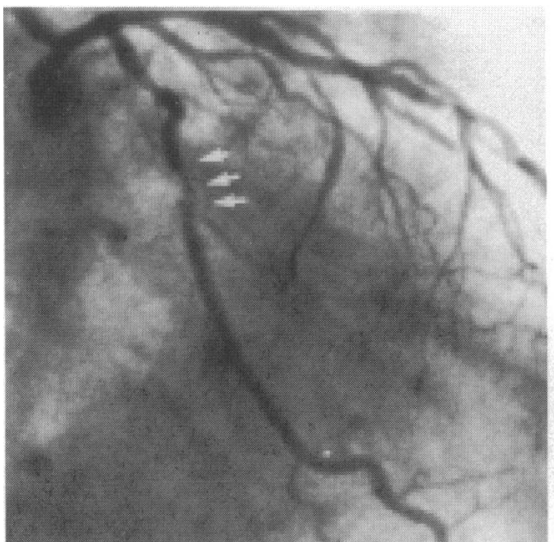

A

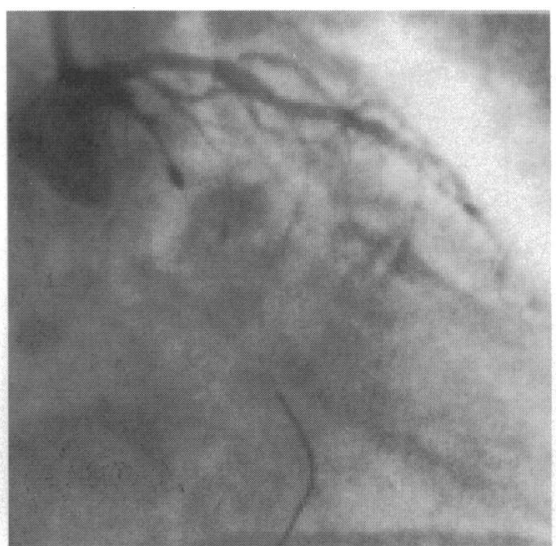

B

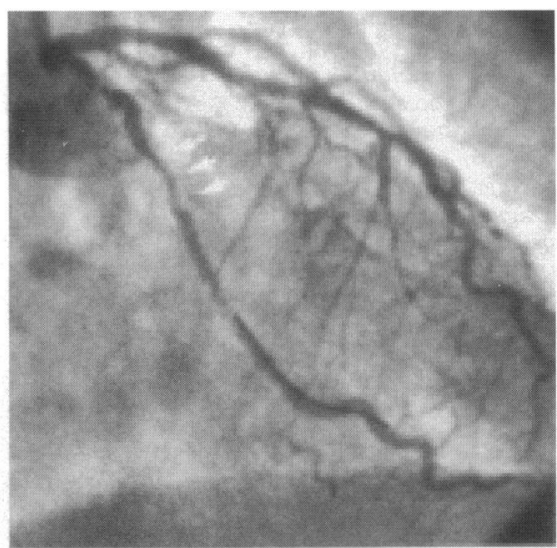

C

Figure 1 Eccentric, irregularly shaped stenosis of the left circumflex $(A)$, which was treated with a $1.75 \mathrm{~mm}$ burr as a stand alone procedure (B). $A$ concentric lumen was created with only a minimal residual stenosis (C).

Figure 2 Stenosis of left anterior descending artery (12 mm long) (A), which was treated with a $2.0 \mathrm{~mm}$ burr as a stand alone procedure (B). Result of intervention was good (C) and nearly unchanged at 6 months (D).

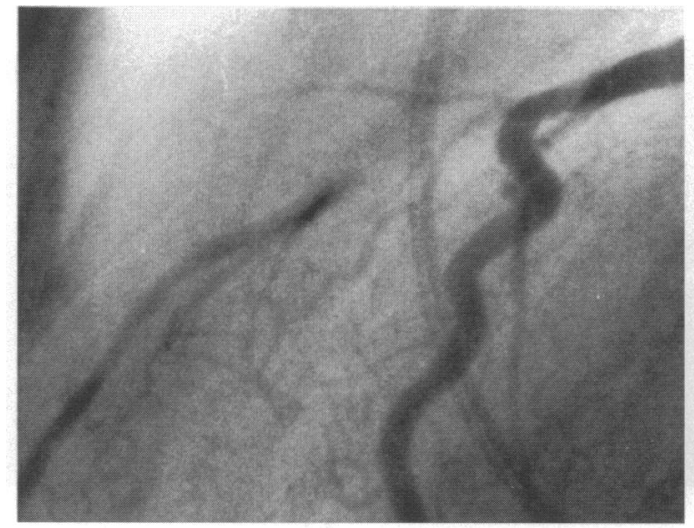

A

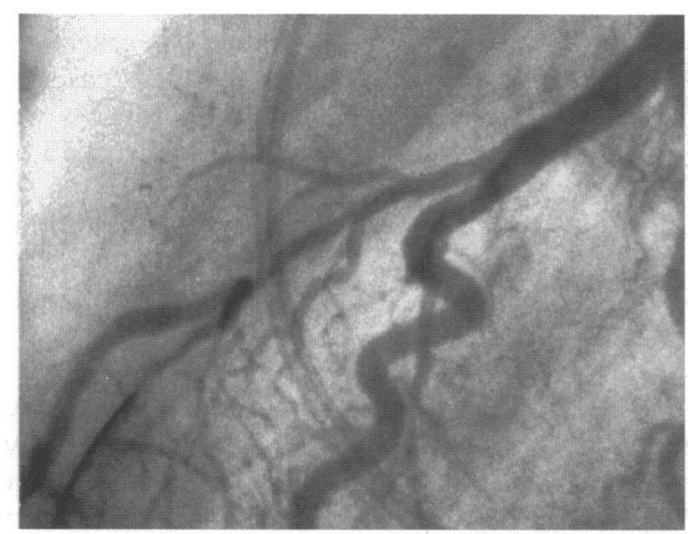

C

severe cardiac events after additional balloon angioplasty.

Cases in which initial treatment was not successful were analysed in terms of whether the biggest burr used was too small for the lesion or whether the effect of rotational ablation was less than expected. To determine whether the burr was big enough to reduce the diameter stenosis to below $50 \%$, the virtual vessel diameter in the stenosis area $\left(D_{0}\right)$ was calculated and compared with the diameter of the used burr ( $\mathrm{Db}$ ) according to the formula $\left(\mathrm{D}_{0}-\mathrm{Db} / \mathrm{D}_{0}\right) \geqslant 0 \cdot 5$. Restenosis was defined as a reduction in luminal diameter of $\geqslant 50 \%$ and a loss of $\geqslant 50 \%$ of the initial success.

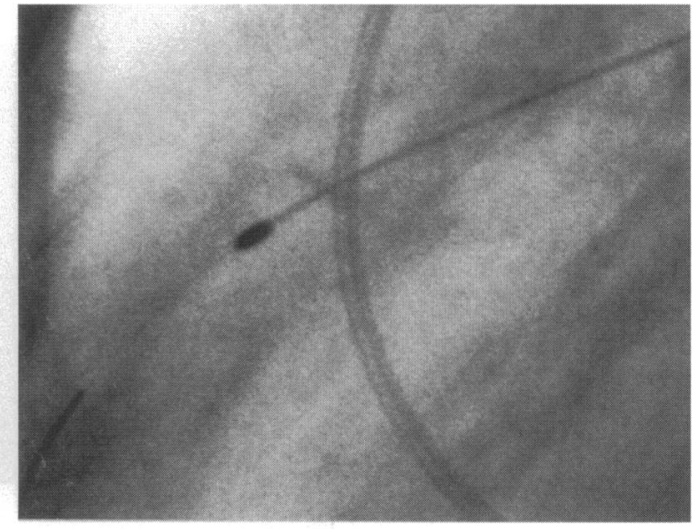

B

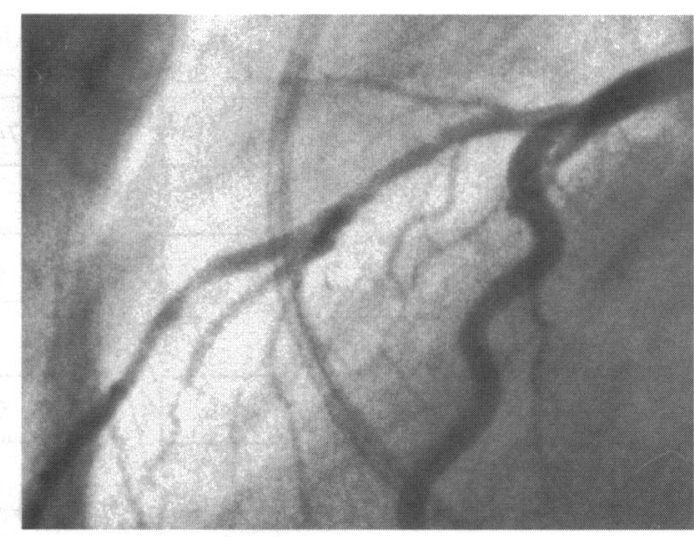

D

\section{STATISTICS}

Results are summarised as means (SD). The level of significance was determined by a paired $t$ test. Differences were considered to be significant when $\mathrm{p}<0.05$.

\section{Results}

\section{SUCCESS RATES}

The Rotablator system could not be used in five stenoses and 16 occlusions (failure to reach or cross the lesion with the guide wire). Primary angiographic and clinical success (see Methods) was achieved in the treatment of 40 of the $67(60 \%)$ stenoses and 18 of the 
Figure 3 Chronic occlusion of a proximal left anterior descending artery (A) and successful recanalisation with a 1.25 mm burr (B). After passage of a $1.75 \mathrm{~mm}$ burr a significant residual stenosis was left (C) which was almost completely removed after balloon angioplasty with $a$ $3.0 \mathrm{~mm}$ balloon (D).

Vessel surface was smooth with no dissection visible.

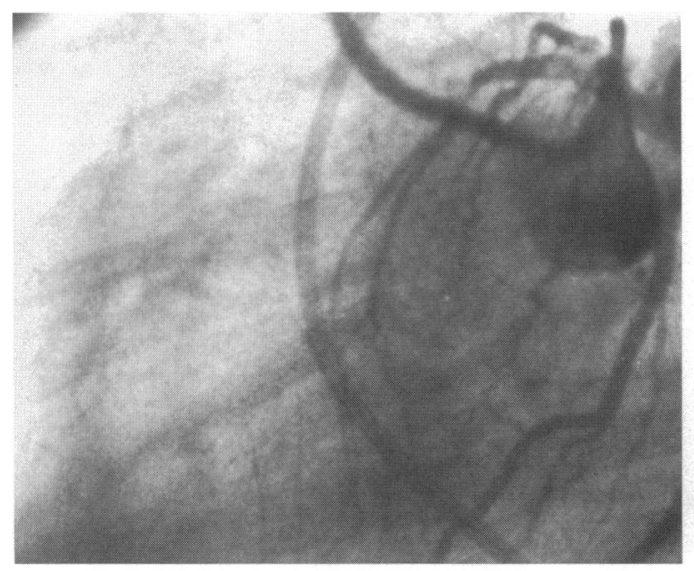

A

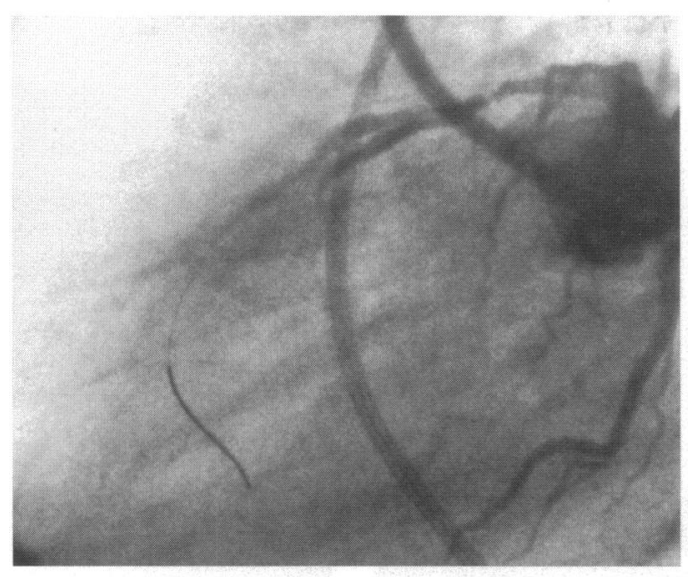

C

\section{Clinical outcome}

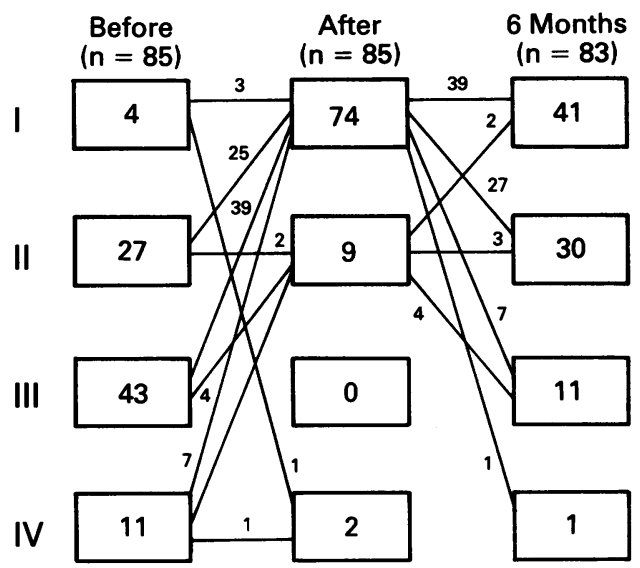

Figure 4 Symptomatic status, ranked according to classification of Canadian Cardiovascular Society. Before treatment six patients presented with unstable angina. The symptomatic status improved after treatment in all patients apart from in two patients, one with symptomatic dissection and one with ongoing infarction.

46 (39\%) chronic occlusions. Figures 1 and 2 show typical examples of successful treatment of a stenosis and an occlusion. In four cases the burr passed the lesion but failed to have a measurable effect. In three of these patients PTCA was successful. The reasons for lack of angiographic success were $(a)$ that the biggest burr available was too small for the lumen (12 cases). (b) that there was an inadequate effect (see Methods) - that is, the new lumen diam-

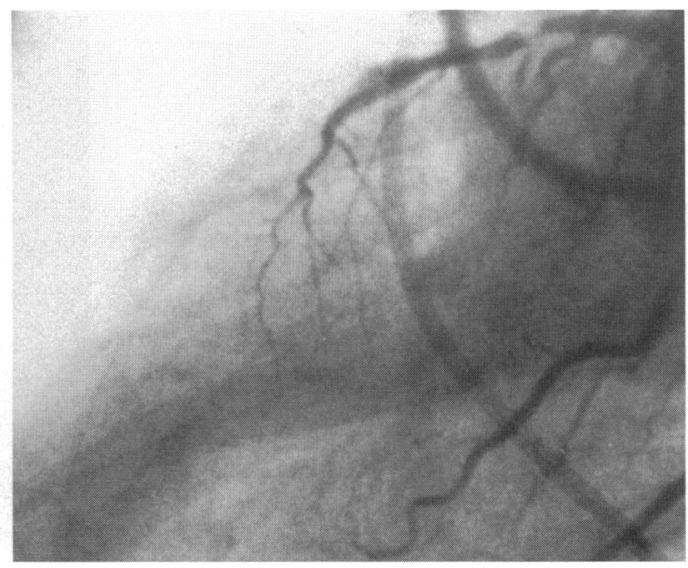

B

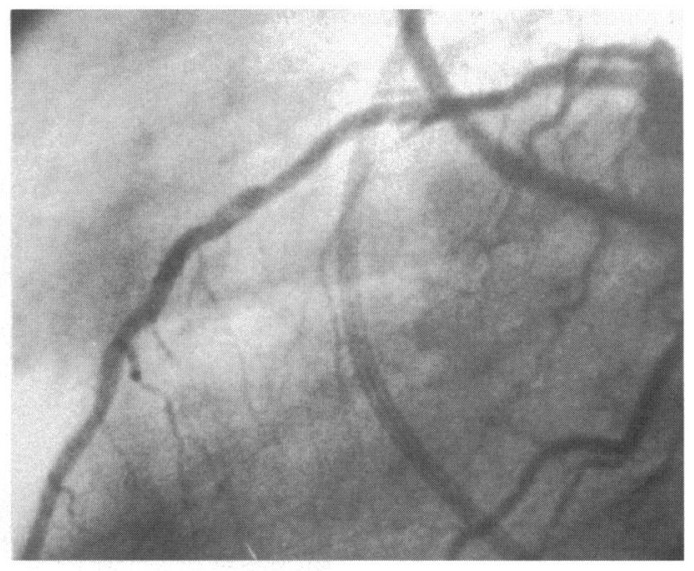

D

eter was less than or equal to half the burr diameter (six cases) - and (c) there was severe spasm (seven cases). In all of these cases additional PTCA was performed, yielding overall success in 53 out of $67(79 \%)$ stenoses and in 25 out of 46 (54\%) occlusions (fig 3). To optimise the outcome PTCA was also carried out in 20 patients in whom rotational ablation was successful.

\section{CLINICAL DATA}

Rotational ablation was used in 85 out of 106 patients, most of whom had symptoms in class II or III according to the Canadian Cardiovascular Society classification (fig 4). All but two patients were symptom free after treatment. In one patient a severe dissection compromised blood flow and caused symptoms; this patient underwent an emergency bypass operation. The patient treated during ongoing myocardial infarction and cardiogenic shock (see below), had symptoms, although the occluded vessel was recanalised.

Major cardiac events (reintervention, myocardial infarction, death) occurred in three $(3 \%)$ patients in hospital and in three patients during the six month follow up period. Figures 5 and 6 show outcome of the intervention.

\section{ANGIOGRAPHIC DATA}

In the lesions treated by rotational ablation the angiographic diameter stenoses were 


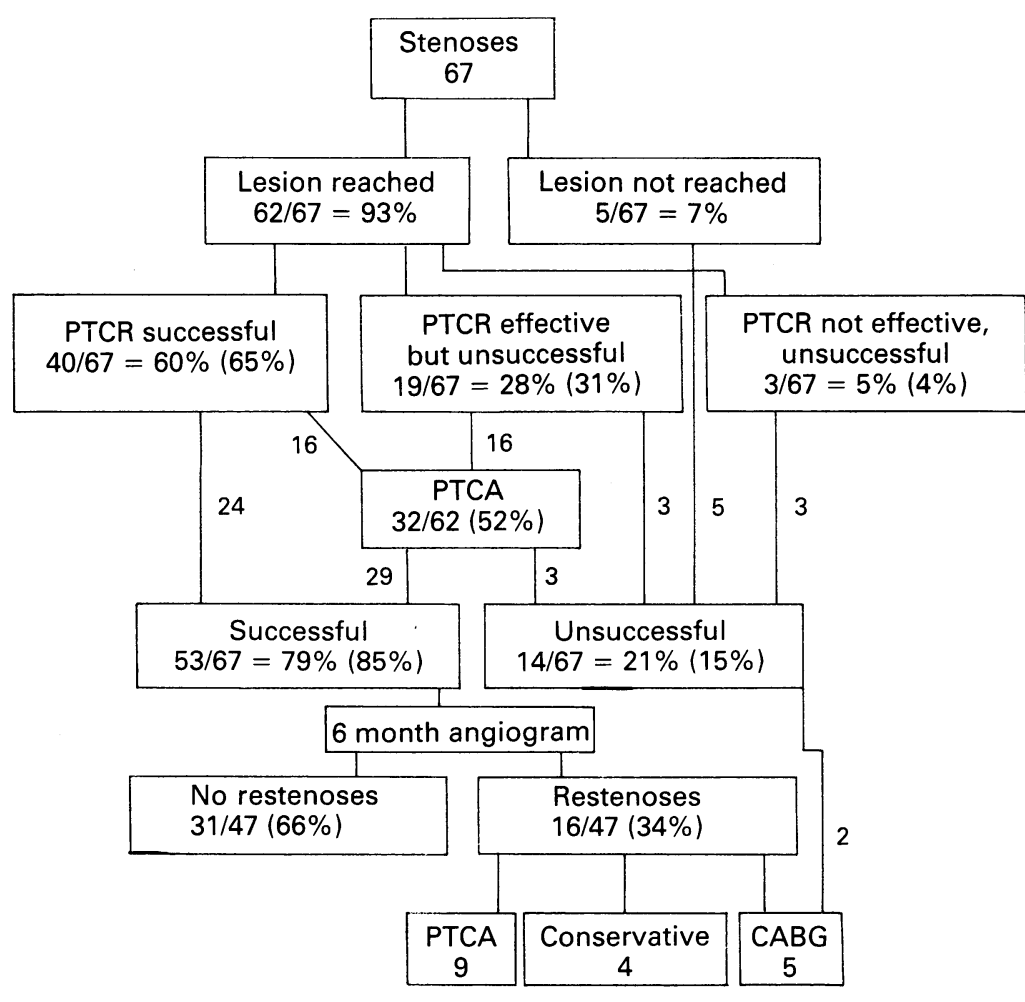

Figure 5 Short and long term outcomes of all stenoses treated. For definitions of interventional success and restenosis see methods. In five lesions not reached Rotablator guide wire could not reach or pass the stenosis. Numbers in parentheses are lesions reached. Rotational ablation was not effective in three lesions in which diameter stenosis was unchanged after intervention. Two cases were clinically unsuccessful, one patient experiencing a severe dissection and one subacute occlusion; both subsequently underwent emergency bypass grafting. PTCR, rotational ablation; PTCA, balloon angioplasty; $C A B G$, coronary artery bypass grafting.

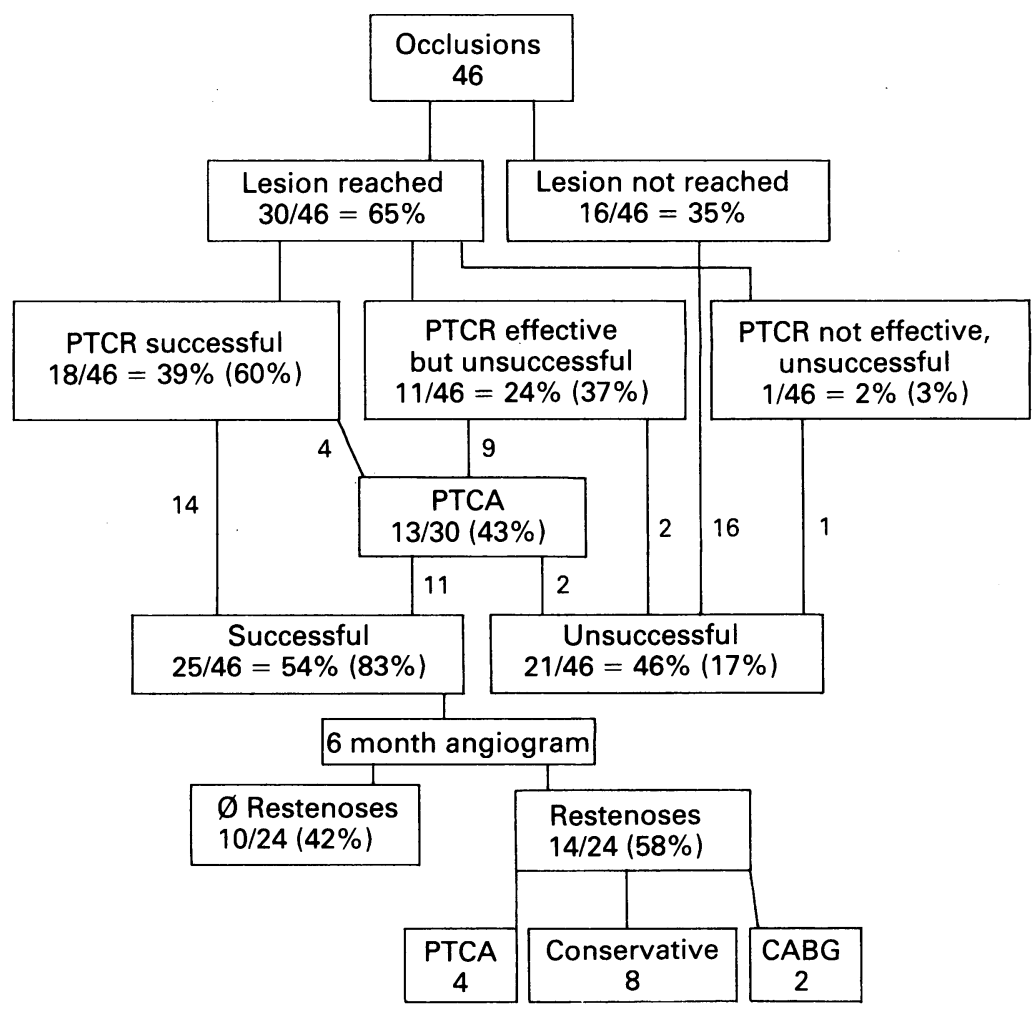

Figure 6 Short and long-term outcomes of all occlusions treated. For definitions of interventional success and restenosis see methods. In 16 lesions not reached Rotablator guide wire could not reach or pass the stenosis. Numbers in parentheses are lesions reached. Rotational ablation was not effective in one lesion in which diameter stenosis was unchanged after intervention. In one patient treated during ongoing infarction angiographical result was unsuccessful; patient died of a large infarction. PTCR, rotational ablation; PTCA, balloon angioplasty; $C A B G$, coronary artery bypass grafting. reduced from $76 \%(13 \%)$ to $42 \%(15 \%)$ in all stenoses and from $100 \%$ to $59 \%(14 \%)$ in all chronic occlusions (diameter stenoses are shown in detail in figures 7-9 and in table 1). In the lesions treated without balloon angioplasty comparison of diameter stenoses immediately after rotational ablation and after 24 hours showed a continued reduction in 22 out of 39 cases, specifically a decrease of $13 \%$ $(12 \%)$. In four cases there was no change in the diameter stenosis after intervention and in 13 cases the diameter stenosis increased by $9 \%(6 \%)$. Overall, there was a reduction of $4 \%$ in the diameter stenosis after intervention $(\mathrm{p}<0.01)$. Luminal diameter increased from $0.7(0.3) \mathrm{mm}$ to $1.5(0.4) \mathrm{mm}$ for all stenoses and from 0 to $1.2(0.4) \mathrm{mm}$ for chronic occlusions. We used different burr tip sizes in steps to remove plaque material in occlusions and in high grade stenoses of large vessels. One size was used for 37 lesions, two sizes for 46 , three sizes for seven, and four sizes for two.

Balloon angioplasty was performed in addition to rotational ablation in 45 lesions, or $48 \%$ of lesions treated. In 20 cases in which primary rotational ablation was successful the diameter stenoses were further reduced from $44 \%(6 \%)$ to $33 \%(15 \%)$ by balloon angioplasty. Adjunctive balloon angioplasty, performed in 25 cases in which rotational ablation was not successful, reduced the diameter stenosis after intervention from $63 \%$ $(13 \%)$ to $38 \%(20 \%)$.

\section{SIDE EFFECTS AND COMPLICATIONS}

A transient bradycardia or a transient atrioventricular block that appeared 1-2 seconds after the start of burr rotation and diminished a few seconds after treatment stopped was seen in nine patients, particularly when the right coronary artery was the target vessel. Ventricular fibrillation occurred during the procedure in one patient with severe three vessel disease and was terminated by defibrillation. In seven patients severe coronary artery spasm nearly occluded the vessel. In five cases of ischaemic reaction balloon dilatation overcame the spasm; in two other cases the spasm relaxed spontaneously after 5-10 minutes but reappeared when another procedure was performed (fig 10). One patient developed symptoms of pericarditis after successful treatment of an occlusion and a stenosis of a bifurcational lesion. Angiographically visible dissections were seen in four cases after rotational ablation and in five cases after additional balloon angioplasty. Major haemorrhage at the puncture site in the groin with a fall in haemoglobin concentration of more than $2 \mathrm{~g} / 1$ was seen in 10 patients.

In another patient rotational ablation caused a major dissection that compromised blood flow. He had an emergency bypass operation and suffered a non- $Q$ wave infarction. Another patient who was symptom free after the intervention developed symptoms of acute myocardial infarction three days after the intervention and shortly after stress test- 
Table 1 Mean (SD) diameter stenosis (percentage) for stenoses treated by rotational ablation (PTCR) alone and with additional balloon angloplasty (PTCA) and of all occlusions. Within the groups data were compared for statistically significant differences

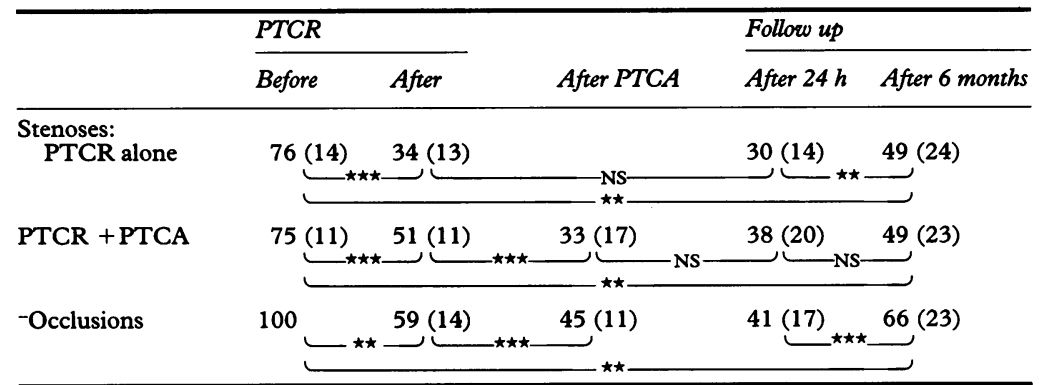

${ }^{\star} \mathrm{p}<0.05,{ }^{\star \star} \mathrm{p}<0.01,{ }^{\star \star \star} \mathrm{p}<0.001 . \mathrm{NS}=$ not significant.

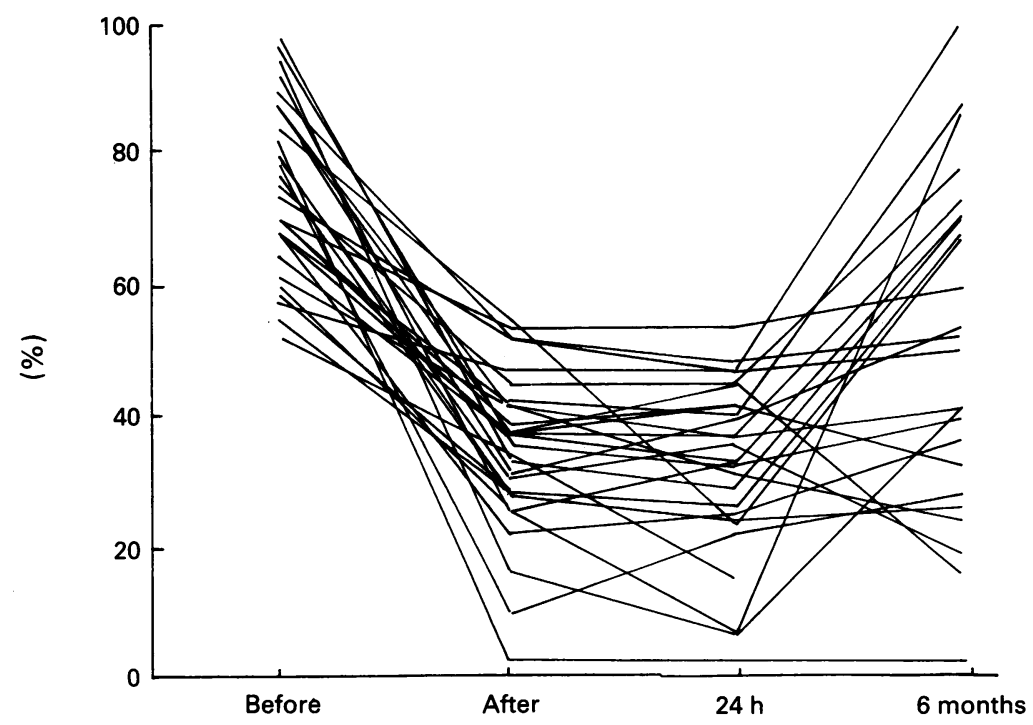

Rotational angioplasty

Figure 7 Individual angiographic outcomes of 27 stenoses treated with rotational ablation. In one patient angiography was not performed after $24 \mathrm{~h}$.

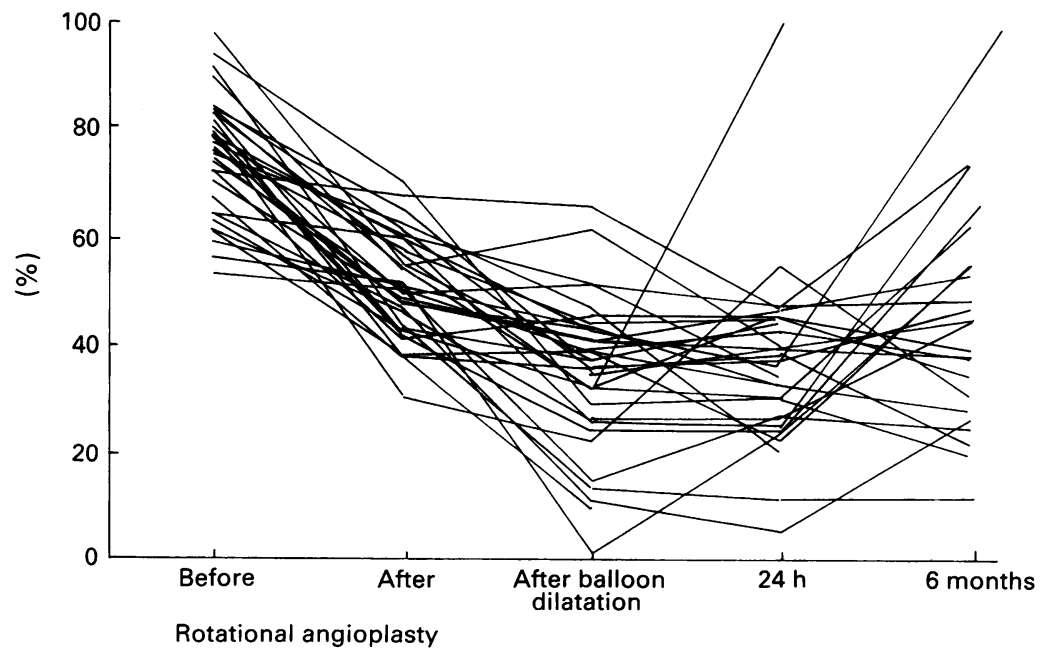

Figure 8 Individual angiographic outcomes of 32 stenoses treated with rotational and balloon angioplasty. In two patients angiography was not performed after $24 \mathrm{~h}$.
Table 2 Side effects and complications of rotational ablation

\begin{tabular}{|c|c|}
\hline Complication & No of patients \\
\hline \multicolumn{2}{|c|}{ Minor } \\
\hline Bradycardia & 7 \\
\hline Transient AV block & 2 \\
\hline Ventricular fibrillation & 1 \\
\hline Coronary artery spasm & 7 \\
\hline Pericarditis & 1 \\
\hline Coronary artery embolism & 2 \\
\hline Dissection & 9 \\
\hline Groin bleeding/haematoma & 10 \\
\hline Rise in creatine kinase & 5 \\
\hline \multicolumn{2}{|c|}{ Major } \\
\hline Subacute occlusion & 2 \\
\hline Emergency CABG & 2 \\
\hline Non-Q wave infarction & 5 \\
\hline Death & 1 \\
\hline
\end{tabular}

$\mathrm{AV}$, atrioventricular. $\mathrm{CABG}$, coronary artery bypass grafting.

ing $(200 \mathrm{~W})$ that gave negative results; he underwent an emergency operation. This patient also suffered a non- $Q$ wave infarction, as did two patients who had angiographically verified embolism. A collateralised previously subtotal stenosis was found to be occluded at the 24 hour examination. It was reopened but a non-transmural infarction resulted. In the five patients with a non- $Q$ wave infarction the maximum rise in creatine kinase concentration was 348 (107) U/1. In another five patients a slight rise in creatine kinase activity (273 (121)U/l) and in creatine kinase MB type activity $(10(6) \mathrm{U} / \mathrm{l})$ was observed but without any electrocardiographic abnormalities or apparent angiographic causes. The patient treated during ongoing myocardial infarction (see below) died after the procedure from a large infarct. Table 2 lists the major complications.

\section{ROTATIONAL ABLATION DURING ONGOING INFARCTION}

A 30 year old obese man with juvenile onset diabetes and a history of smoking was admitted to hospital with a subacute anterior myocardial infarction. Because of persisting unstable angina, ST segment elevation, and early cardiogenic shock he underwent angiography two days later. Massive left ventricular dysfunction and proximal occlusion of the left anterior descending artery were evident. Although passage with a guide wire was achieved a balloon catheter could not be advanced across the lesion. Therefore rotational angioplasty was used and recanalisation was successful, reducing the stenosis to $74 \%$. It was decided to proceed with balloon angioplasty, but although several dilatations were performed a residual stenosis of $55 \%$ was evident. The clinical condition of the patient did not improve and multiorgan failure developed because of permanent cardiogenic shock. He died 24 hours later without clinical evidence of renewed vessel occlusion.

\section{RESTENOSES}

Angiography was performed again after six (2) months in $88 \%$ and $96 \%$ of the patients who had had successful treatment of stenoses and occlusions, respectively. Seven patients refused a repeat angiography, all were free of 
Table 3 Restenoses rates (percentages) calculated according to different definitions ${ }^{18}$

\begin{tabular}{|c|c|c|c|c|}
\hline Definition of restenosis & All stenoses & PTCR stenoses & $\begin{array}{l}P T C R+P T C A \\
\text { stenoses }\end{array}$ & Occlusions \\
\hline \multirow{5}{*}{$\begin{array}{l}\geqslant 50 \% \text { diameter stenosis and } \geqslant 50 \% \text { loss of } \\
\text { initial reduction } \\
>30 \% \text { increase in diameter stenosis (grade })^{\star} \\
\geqslant 70 \% \text { diameter stenosis (of a postinterventional } \\
<50 \% \text { diameter stenosis) (grade II) } \\
\text { Decrease in diameter at follow up within } 10 \% \text { of } \\
\text { preinterventional diameter (grade III) } \\
>50 \% \text { Loss of postinterventional diameter } \\
\text { (grade IV) } \\
>0.72 \text { mm Reduction in luminal diameter compared } \\
\text { with the postinterventional result }\end{array}$} & $\begin{array}{l}34 \\
30\end{array}$ & $\begin{array}{l}36 \\
36\end{array}$ & $\begin{array}{l}32 \\
23\end{array}$ & $\begin{array}{l}58 \\
58\end{array}$ \\
\hline & 21 & 20 & 23 & 58 \\
\hline & 28 & 28 & 27 & 33 \\
\hline & 30 & 36 & 23 & 50 \\
\hline & 31 & 37 & 24 & 54 \\
\hline
\end{tabular}

PTCR, rotational ablation; PTCA, percutaneous transluminal coronary angioplasty. *National Heart, Lung and Blood Institute grading system.

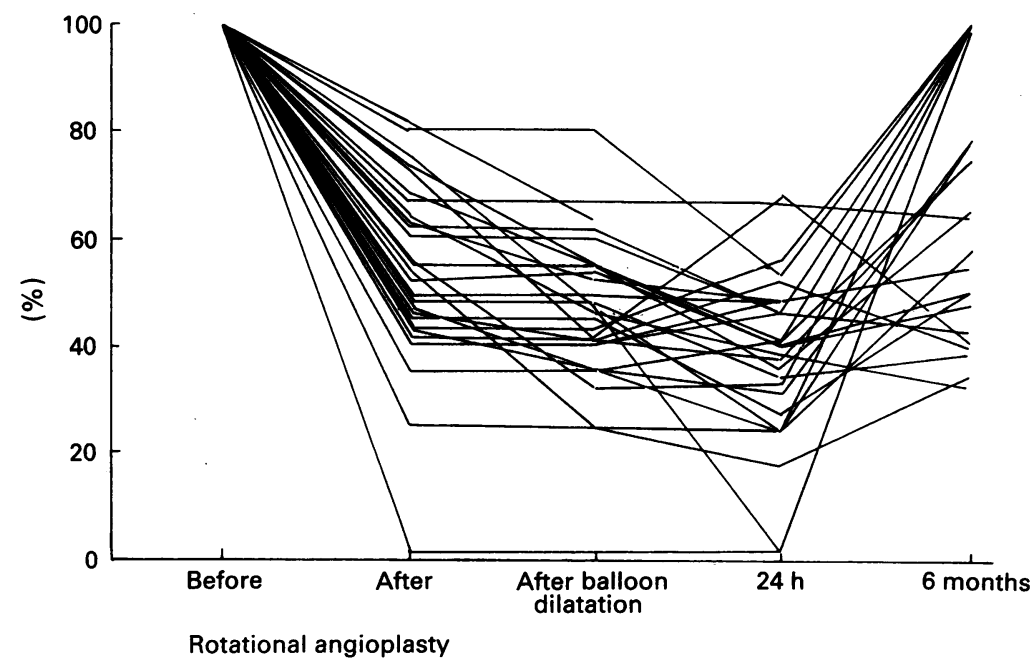

Figure 9 Individual angiographic outcomes of all occlusions treated. In two patients no angiography was not performed after $24 \mathrm{~h}$. symptoms. One patient was restudied after one month because of unstable angina; the original occlusion had reoccluded and was successfully dilated.

In the occlusion group seven out of 24 lesions were reoccluded and seven restenosed. In the stenosis group that underwent rotational ablation alone eight out of 25 lesions were restenosed and one was occluded. In the stenosis group treated with both rotational and balloon angioplasty five out of 22 lesions were restenosed and two were occluded. Progression of coronary artery disease was evident in 12 patients over the six months of follow up. Table 3 shows the rates of restenoses.

\section{Discussion}

Previous investigations indicated that rotational ablation yields angiographic results comparable with those of percutaneous

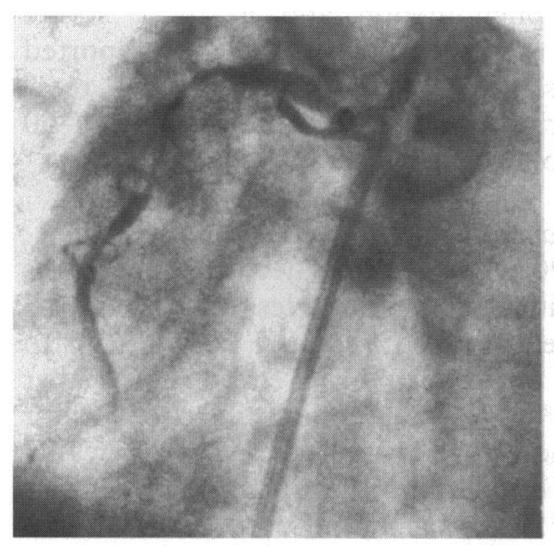

A

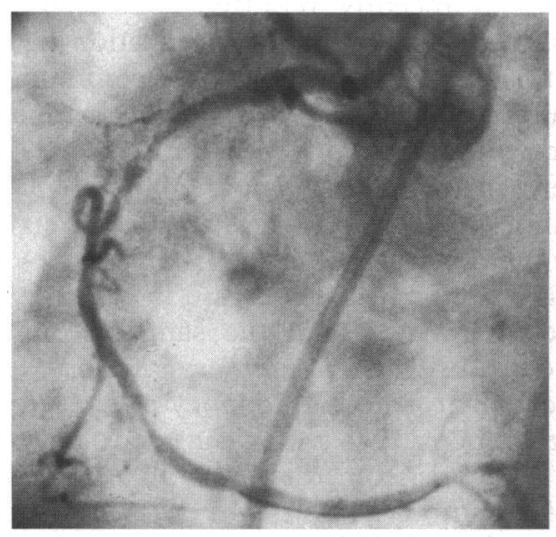

D

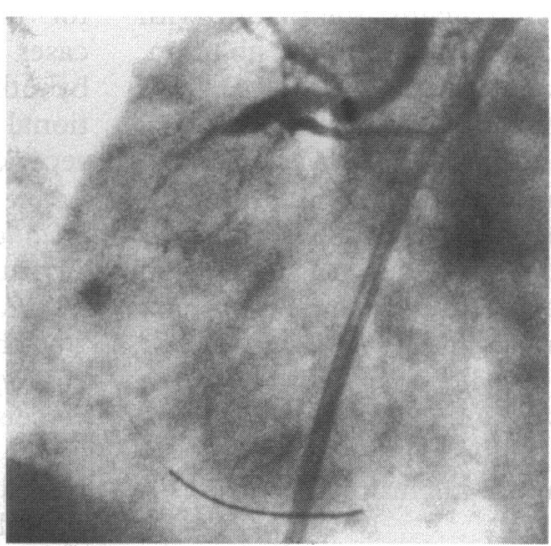

B

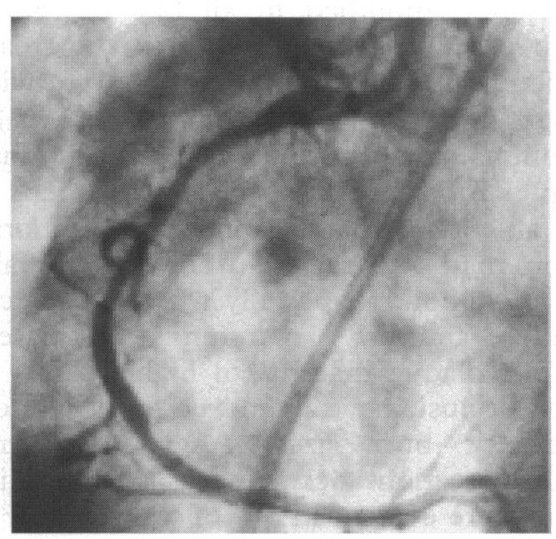

$E$

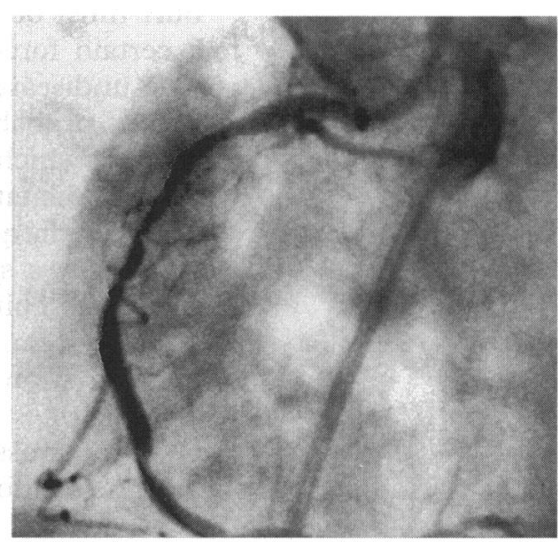

C

Figure 10 Long subtotal stenosis of right coronary artery $(A)$, treatment with $1.5 \mathrm{~mm}$ burr caused severe spasm that nearly occluded the vessel (B): this relaxed after five min $(C)$. A larger burr $(2.0 \mathrm{~mm})$ caused repeated spasm (D), with spontaneous relaxation after some minutes (E). 
transluminal coronary angioplasty. ${ }^{3151619}$ Because of its mechanism of action rotational ablation seems to be advantageous in calcified, long, and high grade lesions. In these complicated lesions the success rates of interventional methods are still low-that is, $60 \%$ $80 \% .^{1-319} \mathrm{We}$ chose such complicated lesions for our study and achieved success rates for rotational ablation that are comparable with those for percutaneous transluminal coronary angioplasty. In almost half of all the cases the outcome of rotational ablation was sufficient for it to serve as a stand alone procedure. With the combined use of rotational ablation and balloon angioplasty success rates of about $80 \%$ can be achieved for stenoses. Failure to achieve angiographic success was the result of procedural limitations in most instances. Firstly, with some early catheter systems over the wire exchange was not possible; with newer, modified devices exchange and positioning can be done quickly and readily. Secondly, burr size was limited in our series to a diameter of $2.0 \mathrm{~mm}$; for proximal lesions bigger burr sizes are needed. Recently, devices with burr tips up to $2.5 \mathrm{~mm}$ have become available, but they require a 10 French introducing sheath and catheter. Thirdly, there were some lesions in which rotational ablation achieved no or an inadequate reduction in size of the stenosis. Although no uniform lesion morphology was found in these cases, the main feature in angiographically unsuccessful cases was extreme lesion eccentricity or a low ratio of burr to vessel diameters. We think that the burr must be pressed against the plaque with a certain force to achieve sufficient ablation. The undiseased vessel wall of some eccentric lesions probably fails to give the burr enough support which allows it to slip past the lesion, causing dilatation rather than ablation.

High frequency rotational ablation is guided by a special wire, which is somewhat more difficult to position in the coronary artery system. To facilitate positioning we use recanalisation catheters. Because the Rotablator is a wire guided system failure to reach or cross the lesion was the most common reason for failure in chronic occlusions.

\section{EFFECTS AND EFFECTIVENESS}

The diameter stenoses were reduced and angiographic contours smoothed in all but four lesions. The cases in which rotational ablation was inadequate showed no particular common angiographic finding. Residual stenosis after rotational ablation could be due to persisting plaque or to spasm (see below).

In addition to ablation of plaque material, rotational ablation may also result in some degree of plaque dilatation, ${ }^{13}$ especially when the burr is advanced too fast. To minimise this dilatatory effect plaque material of high grade stenoses and occlusions was removed in steps using different burr sizes. Angiographically visible dissections occurring as a result of dilatation were evident in $5 \%$ of the cases after rotational ablation. The low incidence of dissections after additional bal- loon angioplasty $(6 \%)$ may be the result of the preceding removal of the rigid vessel wall layer and plaques and the reduction in diameter stenosis. As dissections considerably increase the risk of major complications ${ }^{20-22}$ our approach may have contributed to the low complication rate.

Currently there are three methodological hazards connected with rotational ablationnamely, microcavitations, ablation debris, and spasm.

\section{Microcavitations}

The movement of a body at high speed in a fluid causes dissolved gases to come out of solution. A burr tip with a rotational frequency of more than $34000 \mathrm{rpm}$ generates microbubbles with a random size of 90 (33) $\mu \mathrm{m} .{ }^{23}{ }^{24}$ These microbubbles can be visualised sonographically during rotational ablation by echo enhancement of the myocardial region being treated ${ }^{24}$ and, depending on the number produced, might have some clinical relevance by causing a short lasting obstruction of capillaries until the gases dissolve again. Microcavitations therefore are very likely to be the reason for transient ST segment depressions and many common rhythm problems. The prophylactic administration of atropine reduced the frequency and intensity of bradycardia and atrioventricular block. In some cases the coronary flow seemed to be reduced immediately after rotational ablation, improvement coming after several minutes. Obstruction of larger parts of the capillary bed by microbubbles is likely to be the reason for this phenomenon and in more severe cases for the no reflow phenomenon reported by others. ${ }^{25} \mathrm{We}$ therefore limited each rotational series to 10 seconds and waited 30-60 seconds between series.

\section{Ablation debris}

About $90 \%$ of the ablated plaque forms pieces with a diameter of less than $5 \mu \mathrm{m} .{ }^{26}{ }^{27}$ But there may also be some particles up to $250 \mu \mathrm{m}$, which can form emboli in smaller vessels. ${ }^{28} 29$ We saw emboli in two of our cases: one was proximal to the lesion treated in a side branch of a diagonal branch, and in the other the distal run off was blocked after a long occlusion was removed using four burr sizes.

Klein et al recently reported that slight increases in creatine kinase concentration up to twice the normal upper value are common (15\%) after successful percutaneous transluminal coronary angioplasty ${ }^{30}$; in many cases there were neither clinical nor angiographic abnormalities so atherosclerotic debris is probably the origin of the emboli. ${ }^{31-34}$ The frequency and extent of the increase in creatine kinase activity were about the same in our study group. Friedman et al have reported isolated clusters of necrotic myocytes caused by microembolisation after intracoronary injection of debris from rotational ablation in dogs. ${ }^{29}$ Microembolisation might be the cause of the unexplained slight increase in creatine kinase we found in four of five patients. 
A considerable drop in rotational frequency during passage through a lesion is more common when one large burr is used than when a stepwise approach is used (see above). As particle size increases when the rotational frequency drops below 150000 $\mathrm{rpm}$, more complications from microembolisation and macroembolisation can be expected. ${ }^{25}$

\section{Spasm}

We and others ${ }^{35}$ often see coronary artery spasm after rotational ablation but spasm is also common with balloon angioplasty. ${ }^{36} 37$ The reactivity and muscular tone of diseased epicardial arteries are impaired according to the degree of the atherosclerotic changes. Disturbed release of endothelium-derived relaxation factor and prostacyclin may account for the imbalance between factors (cellular and humoral) regulating vascular muscle tone. ${ }^{38-40}$ Atherosclerotic segments thus react to vasoconstricting agents more readily and intensively than normal segments. ${ }^{4142}$ Altering the endothelial-subendothelial regulatory system by partial removal of the intima or denudation of subintimal tissue, or both, leads to an excessive reaction mainly caused by platelet derived factors (thromboxane $A_{2}$, serotonin) and endothelium derived factors (endothelin), whose release is induced by the cell injury. ${ }^{43-45}$ Moreover, the vasoactive response depends on the extent of thrombus formation and the underlying atherosclerosis. ${ }^{43}$ The frequency with which spasm occurs during interventional procedures thus depends on the aggressiveness of the procedure and the underlying lesion. In our group of patients there was a significant trend towards wider luminal diameters at 24 hour control angiography, suggesting a postinterventional release of increased vessel tone. Severe spasm was not countered by intracoronary nitrates; in the cases with an ischaemic reaction spasm was overcome by balloon dilatation, which was easy to perform with an over the wire system. Recent investigations indicate that nitrates and other vasodilators have little effect on injury-related vasoconstriction, ${ }^{46} 47$ with the exception of calcium channel blockers, whose smooth muscle relaxing effect was preserved. ${ }^{48} \mathrm{We}$ believe that intravenous calcium channel blockers should be given for 24 hours before the intervention.

\section{PROCEDURE RELATED DEATHS}

The patient who died 24 hours after the procedure was the only patient in whom rotational ablation was performed during myocardial infarction. Rotational ablation was performed as a bail out procedure and the patient was already in cardiogenic shock. Although the intervention was not successful according to standard angiographic criteria, vessel perfusion was restored. The patient died of the large infarct, and in our opinion interventional treatment did not affect the clinical course. The case shows that rotational ablation can be used in acute occlusion that cannot be passed with a balloon catheter.

\section{RESTENOSIS}

There is evidence that the fibrocellular response to vessel damage causing restenosis strongly depends on the extent of thrombus formation and subsequent release of growth factors. ${ }^{4550}$ Moreover, the exposure of deeper vessel wall layers seems to provoke a stronger proliferative response. ${ }^{5152}$ In heavily diseased coronary arteries and in high grade stenosis balloon angioplasty puts great shear stress on the vessel wall and is more likely to cause deep vascular injury. ${ }^{5354}$ Rotational ablation, properly used, does little harm to the subintimal layers, ${ }^{12}$ which suggests that it has a less stimulating effect on the restenosis process. At present the restenosis rate for stenoses treated with rotational ablation alone is within the lower range of data reported for the treatment of comparable lesions with balloon angioplasty. ${ }^{2-4}$ The restenosis rate after the combined use of both procedures is lower, but not significantly. The larger number of suboptimal results that remained in the rotational ablation group may be a cause of this discrepancy, though the means for diameter stenoses after intervention were not different between the two groups.

\section{CONCLUSION}

This investigation showed that high frequency rotational ablation can be used in complicated stenoses and occlusions. Initial angiographic success, the reduction in diameter stenosis and the complication rate were about the same as with balloon angioplasty. In $48 \%$ of our cases we also performed balloon angioplasty to achieve angiographic success or optimise the result. The combination of rotational and balloon angioplasty was feasible and safe. The incidence of dissections and resulting complications was very low after additional balloon angioplasty for type B and $C$ lesions. This may be a result of initial debulking of atherosclerotic material by rotational ablation.

1 Cowley M, Dorros G, Sherly F, Kelsey F, van Raden M, Detre KM. Emergency coronary bypass surgery after coronary angioplasty: the National Heart, Lung and Blood Institute's percutaneous transluminal coronary angioplasty registry experience $\mathrm{Am} 7$ Cardiol 1984;53: 22-6C.

2 Ellis SG, Topol EJ. Results of percutaneous transluminal coronary angioplasty of high-risk angulated stenoses. Am $₹$ Cardiol 1990;66:932-7.

3 Ryan TJ, Faxon DP, Gunnar RM, Kennedy W, King SB III, Loop FD, et al. Guidelines for percutaneous transII, Loop FD, et al. Guidelines for percutaneous transluminal coronary angioplasty. A report of the American
College of Cardiology/American Heart Association. f Am Coll Cardiol; 1988;12:529-45.

4 Savage MP, Goldberg S, Hirshfeld JW, Bass TA MacDonald G, Margolis JR, et al. Clinical angiographic determinants of primary coronary angioplasty success. f Am Coll Cardiol 1991;17:22-8.

5 Kensey KR, Nash JE, Abrahams C. Recanalisation of obstructed arteries with a flexible, rotating tip catheter. Radiology 1987;165:387-9.

6 Stack RS, Quigley PJ, Sketch MJH, Stack RK, Walter K, Hofmann PU, et al. Treatment of coronary artery disease with case Circulation 1989:80:583.

7 Ahn SS, Auth DC, Marcus P, Moore WS. Removal of focal atheromatous lesions by angioscopically guided high-speed rotatory atherectomy: preliminary experimental observations. 7 Vasc Surg 1988;7:292-300. 
8 Hansen DD, Auth DC, Vracko R, Ritchie JL. Rotational atherectomy in atherosclerotic rabbit iliac arteries. $\mathrm{Am}$ Hear $₹$ 1988;116:160-5.

9 Hansen DD, Auth DC, Hall M, Ritchie JL. Rotational endarthrectomy in normal canine coronary arteries: preliminary report. 7 Am Coll Cardiol 1988;11:1073-7.

10 Hall M, Hansen DD, Intelkofer MJ, Auth D, Ritchie J. PTCA versus rotational atherectomy in rabbit athero-
sclerosis: early and late effects [abstract]. $₹ \mathrm{Am}$ Coll sclerosis: early and lat

11 Fourrier JL, Stankovwiak C, Lablanche JM, Prat A, Brunetaud JM, Bertrand ME. Histopathology after rotational angioplasty of peripheral arteries in human beings [abstract]. $f \mathrm{Am}$ Coll Cardiol 1988;11:109A

12 Dietz $U$, Erbel $R$, Pannen B, Haude $M$, Nixdorff $U$, Iversen $S$, et al. Angiographische und histologische Befunde bei der Hochfrequenzrotationsablation in Koronararterien in vitro. $Z$ Kardiol 1991;80:222-9.

13 Pannen B, Dietz U, Erbel R, Iversen S, Nixdorff U, Meyer J, et al. Ultrastructural changes in coronary arteries after rotational angioplasty. Possible relevance of Dotter effects [abstract]. Eur Heart $¥$ 1989; ;uppl10:323.

14 Erbel $R, O$, Neil W, Auth DC, Haude M, Nixdorff U Rupprecht $\mathrm{HJ}$, et al. High frequency rotablation of Rupprecht HJ, et al. High frequency rotablation of occluded coronary artery during hear

15 Bertrant MF, Lablanche JM, Leroy F, Bauters C, De Jaegere P, Serruys PW, et al. Percutaneous transluminal coronary rotational ablation with Rotablator. $\mathrm{Am} \mathcal{H}$ Cardiol 1992;69:470-4.

16 Dietz U, Erbel R, Rupprecht HJ, Ratz Ch, Weidmann S, Haude $M$, et al. Acute and long-term results after percutaneous transluminal coronary rotational angioplasty [abstract]. Eur Heart 1991;12:291.

17 Braun BG, Bolson E, Frimer M, Dodge HT. Quantitative coronary angiography. Circulation 1977;55:329-37.

18 Serruys PW, Luijten HE, Beatt KJ. Incidence of restenosis after successful coronary angioplasty: a time-related after successful coronary angioplasty: a

19 Detre K, Holubkov R, Kelsey S, Cowly M, Kent K, Williams D, et al. Percutaneous transluminal coronary angioplasty in 1985-1986 and 1977-1981. N Engl $\mathcal{F}$ Med 1988;318:265-70.

20 Ellis SG, Roubin GS, King SB III, Douglas JS, Weintraub WS, Thomas RG, et al. Angiographic and clinical predictors of acute closure after native vessel coronary angioplasty. Circulation 1988;77:372-9.

21 Bredlau CE, Roubin GS, Leimgruber PP, Douglas JS, King S III, et al. In-hospital morbidity and mortality in patients undergoing elective coronary angioplasty. pirculation 1985;72:1044-52.

22 Ischinger T, Gruentzig AR, Meyer B, Galan K. Coronary dissection and total coronary occlusion associated with percutaneous transluminal coronary angioplasty: significance of initial angiographic morphology of coronary tenoses Circulation 1986;4:1371-8.

23 Zotz R, Stähr P, Erbel R, Auth D, Meyer J. Analysis of high frequency rotational angioplasty-induced echo contrast. Cathet Cardiovasc Diagn 1991;22:137-44.

24 Zotz $R$, Wittlich N, Erbel $R$, et al. Erkennung von Kontrast während hochfrequenter Rotablation von arteriosklerotischen Plaques mittels transösophagealer Echokardiographie [abstract]. Z Kardiol 1989;78:(suppl 1): 131 .

25 Tairstein PS, Ginsburg R, Warth DC, Hoqu N, Jenkins NS, McCowan L. Complications of human coronary rotablation [abstract]. $¥$ Am Coll Cardiol 1990;15:57A.

26 Zacca NM, Raizner AE, Noon GP, Short HD III Weilbaecher DG, Gotto $M$. Short term follow up of patients treated with a recently developed rotational atherectomy device and in vivo assessment of the particles generated [abstract]. $\mathscr{f} \mathrm{Am}$ Coll Cardiol 1988;11 $109 \mathrm{~A}$.

27 Prevosti LG, Cook JA, Unger EF, Sheffield CD, Almagor $\mathrm{Y}$, Bartorelly AL, et al. Particulate debris from rotationa atherectomy: size distribution and physiologic effects [abstract]. Circulation 1988;78:83.

28 Zacca NM, Raizner AE, Noon GP, Short D III, Weilbaecher D, Gotto A, et al. Treatment of symptomatic peripheral atherosclerotic disease with rotational atherectomy device. Am 7 Cardiol 1989;63:77-80.

29 Friedman HZ, Elliott MA, Gottlieb GJ, O'Neill WW. Mechanical rotatory atherectomy: the effects of microMechanical rotatory atherectomy: the effects of microparticle embolization on myocardial

30 Klein LW, Kramer BL, Howard E, Lesch M. Incidence and clinical significance of transient creatine kinase elevations and the diagnosis of non- $Q$ wave infarction associated with coronary angioplasty. $\mathscr{f} \mathrm{Am}$ Coll Cardio
1991;17:621-26.

31 Castaneda-Zuniga WR, Sibley R, Amplatz K. The pathologic basis of angioplasty. Angiology 1984;35:195-205.

32 Colavita PG, Raymond E, Ideker RE, Reimer KA, Hacke DB, Stack RS. The spectrum of pathology associated with percutaneous transluminal coronary angioplasty during acute myocardial infarction. I Am Coll Cardiol 1986;8:855-60.

33 Block P, Elmer D, Fallon JT. Release of atherosclerotic debris after transluminal angioplasty. Circulation 1982; debris after

34 Sanborn TA, Faxon DP, Waugh D, Small DM Haudenschild C, Gottsman SB, et al. Transluminal angioplasty in experimental atherosclerosis. Circulation 1982;66:917-22.

35 Zacca N, Heibig J, Harris S, Kleiman N, Staudacher R Smith S, et al. Percutaneous coronary high speed rotational atherectomy: new, but how safe? [abstract]. $\mathscr{f} \mathrm{Am}$ Coll Cardiol 1990;15:58.

36 Bertrant ME, Lablanche JM, Fourrier JL, Gommeaux A, Ruel M. Relation to stenosis after percutaneous transluminal coronary angioplasty to vasomotion of dilated coronary arterial segment. Am $\mathcal{f}$ Cardiol 1989;63: 277-81.

37 Erbel R, Schreiner G, Pop T, Rupprecht HJ, Meyer J. Coronary spasm in patients treated by percutaneous transluminal coronary angioplasty. In: Höfling B, ed Current problems in PTCA. Darmstadt Steinkopf, 1986 75-81.

38 Harrison DG. From isolated vessels to the catheterization laboratory. Circulation 1989;80:703-6.

39 Peterson MB, Machaj V, Block PC, Palacios I, Philbin D, Watkins WD. Thromboxane release during percutaneous transluminal coronary angioplasty. Am Heart $f$ 1986;111:1-6.

40 Chesebro JH, Lam JYT, Badimon L, Fuster V. Restenosis after arterial angioplasty: a hemorrheologic response to injury. Am $₹$ Cardiol 1987;60:10-6B

41 Zeiher AM, Drexler H, Wollschläger H, Just HJ. Modulation of coronary vasomotor tone in humans. Modulation of coronary vasor

42 LaVeau PJ, Sarembock IJ, Sigal SL, Yang TL, Ezekowitz $\mathrm{MD}$. Vascular reactivity after balloon angioplasty in an atherosclerotic rabbit. Circulation 1990;82:1790-801.

43 Lam JYT, Chesebro JH, Steele PM, Badimon L, Fuste V. Is vasospasm related to platelet deposition? Circulation 1987;75:243-8.

44 Brum JM, Sufan Q Lane G, Bove AA. Increased vasoconstrictor activity of proximal coronary arteries with endothelial damage in intact dogs. Circulation 1984;70. 1066-73.

45 Lerman A, Brooks SE, Hallett JW, Heublein DM, Sandberg SM, Burnett JC. Circulating and tissue Sandberg SM, Burnett JC. Circulating and tissue endothelin immunoreactivity in advan.

46 Hollman J, Austin GE, Gruentzig AR, Douglas JS, King SB III. Coronary artery spasm at the site of angioplasty in the first 2 months after successful percutaneous transluminal coronary angioplasty. $\mathcal{F} \mathrm{Am}$ Coll Cardiol 1983;2 $1039-45$.

47 Buxton AE, Goldberg S, Harken A, Hirshfeld J, Kastor JA. Coronary artery spasm immediately after myocardial revascularization. N Engl 7 Med 1981;304: 1249-53.

48 Galle J, Bassenge E. Influence of low-density lipoproteins (LDL) on the reactivity of atherosclerotic arteries. (LDL) on the reactivity of ather

49 Faxon DP, Sanborn TA, Haudenschild CC. Mechanism of angioplasty and its relation to restenosis. Am $\mathcal{F}$ Cardiol 1987;60:5-9B.

50 Wilentz JR, Sanborn TA, Haudenschild CC, Valeri CR, Ryan TJ, Faxon DP. Platelet accumulation in experimental angioplasty: time course and relation to vascula injury. Circulation 1987;75:636-42.

51 Lam JYT, Chesebro JH, Steele PM, Dewanjee MK Badimon L, Fuster V. Deep arterial injury during experimental angioplasty: relation to positive indium111-labeled platelet scintigram, quantitative platelet deposition and mural thrombosis. $\mathfrak{f} \mathrm{Am}$ Coll Cardiol 1986;8:1380-6.

52 Austin GE, Ratliff NB, Hollman J, Tabey S, Phillips DF. Intimal proliferation of smooth muscle cells as an explanation for recurrent coronary artery stenosis after percutaneous transluminal coronary angioplasty. $\mathcal{F} \mathrm{Am}$ Coll Cardiol 1985;6:369-75.

53 Liu MW, Roubin GS, King SB III. Restenosis after coronary angioplasty. Circulation 1989;79:1374-87.

54 Fanelli C, Aronoff R. Restenosis following coronary angioplasty. Am Heart $\mathcal{f}$ 1990;119:357-68. 